\title{
Clinical characteristics and risk factors of tigecycline-associated hypofibrinogenaemia in critically ill patients
}

\author{
Juan $\mathrm{Hu}^{1} \cdot$ Yong-hong Xiao ${ }^{2} \cdot$ Yi Zheng ${ }^{1} \cdot$ Yang-xiao Lai $^{1} \cdot$ Xue-ling Fang $^{1} \cdot$ Qiang Fang $^{1}$
}

Received: 5 November 2019 / Accepted: 26 March 2020 / Published online: 30 April 2020

(C) Springer-Verlag GmbH Germany, part of Springer Nature 2020

\begin{abstract}
Purpose To analyze the clinical features and risk factors of tigecycline-associated hypofibrinogenaemia and study whether cefoperazone/sulbactam combined with tigecycline aggravates coagulopathy or hypofibrinogenaemia.

Methods A retrospective case-control study of patients with severe infection who were treated with tigecycline was conducted. Patients were assigned to the hypofibrinogenaemia group $(<2.0 \mathrm{~g} / \mathrm{L})$ and normal fibrinogen (normal) group $(\geq 2.0 \mathrm{~g} / \mathrm{L})$ to assess the clinical features of patients with tigecycline-associated hypofibrinogenaemia. The traits of patients treated with cefoperazone/ sulbactam in the hypofibrinogenaemia group were also analyzed.

Results In total, 127 patients were enrolled in the study, including 71 patients with hypofibrinogenaemia and 56 patients with normal fibrinogen levels. Hypofibrinogenaemia developed at a median of 6 (4-8) days after tigecycline treatment, and the fibrinogen level returned to normal at a median of $3(3-5)$ days after tigecycline discontinuation. In the multivariate analysis, intra-abdominal infection $(p=0.005)$, fibrinogen level at tigecycline initiation $(p<0.001)$, maintenance dose $(p=0.039)$, and treatment duration $(p=0.002)$ were found to be related to hypofibrinogenaemia. Treatment with cefoperazone/sulbactam was not associated with hypofibrinogenaemia $(p=0.681)$, but patients treated with cefoperazone/sulbactam had a higher incidence of coagulopathy $(p=0.009)$ and needed more blood products $(p=0.003)$ than those treated without cefoperazone/sulbactam.

Conclusion Tigecycline-associated hypofibrinogenaemia often developed on the 6th (4th-8th) day of tigecycline use and was associated with intra-abdominal infection, fibrinogen level at tigecycline initiation, maintenance dose, and treatment duration of tigecycline but not cefoperazone/sulbactam.
\end{abstract}

Keywords Sepsis $\cdot$ Tigecycline $\cdot$ Hypofibrinogenaemia $\cdot$ Coagulation disturbances

\section{Introduction}

Glycylcyclines are molecules that have structural similarities to tetracyclines but are active against tetracycline-resistant organisms. Tigecycline, the first glycylcycline discovered, was approved by the Food and Drug Administration in June 2005 and entered the Chinese market in November 2011. It has been widely used since 2015 [1] and requires intravenous administration with a loading dose of $100 \mathrm{mg}$ followed by $50 \mathrm{mg}$ twice daily. Tigecycline has broad-spectrum activity;
Juan Hu and Yong-hong Xiao contributed equally to this work.

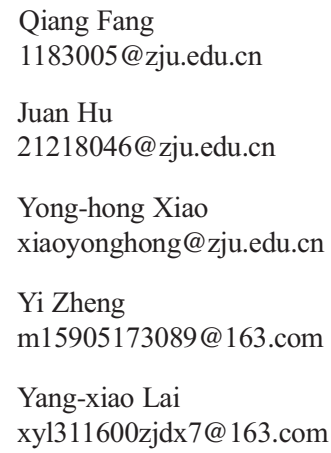

Xue-ling Fang

13588867114@163.com

Intensive Care Unit, The First Affiliated Hospital, College of Medicine, Zhejiang University, 79 Qingchun Road, Hangzhou 310003, People's Republic of China

2 State Key Laboratory for Diagnosis and Treatment of Infectious Diseases, National Clinical Research Center for Infectious Diseases, Collaborative Innovation Center for Diagnosis and Treatment of Infectious Diseases, The First Affiliated Hospital, College of Medicine, Zhejiang University, 79 Qingchun Road, Hangzhou 310003, People's Republic of China 
it inhibits protein synthesis by acting on the $30 \mathrm{~S}$ ribosomal subunit, blocking entry of aminoacyl-transfer ribonucleic acid (RNA) molecules into the ribosome site [2]. Tigecycline is active against resistant pathogens such as methicillinresistant staphylococci, penicillin-resistant Streptococcus pneumoniae, and vancomycin-resistant enterococci [3]. The main indications for tigecycline are complicated intraabdominal infection, complicated skin and skin-and-softtissue infection, and community-acquired pneumonia caused by bacteria sensitive to tigecycline.

Although tigecycline was generally well tolerated in registry trials, its introduction and widespread use have resulted in reports of adverse reactions. The most frequent are nausea, vomiting, diarrhoea, abdominal pain, headache, and an increased alanine aminotransferase level. Less frequent adverse events include increased alkaline phosphatase and total bilirubin levels, prolonged prothrombin time (PT) and activated partial thromboplastin time (APTT), and pancreatitis [3-5]. Among patients who received tigecycline during clinical trials, $<2 \%$ developed coagulopathy [6]. However, only six case reports $[4,7-11]$ and two clinical studies $[5,12]$ performed from 2000 to 2019 have focused on patients who developed hypofibrinogenaemia after tigecycline use, as indicated by an increased international normalized ratio (INR) and prolonged PT and APTT; in these cases, the hypofibrinogenaemia resolved after tigecycline discontinuation.

As high rates of treatment failure among patients treated with the standard of dose tigecycline have been documented [13-15], combination therapy and high-dose tigecycline are the options chosen by many physicians when facing severe infections caused by drug-resistant pathogens. Dong et al. [16] reported that combinations of rifampin/tigecycline and sulbactam/tigecycline show good in vitro activity against extensively drug-resistant Acinetobacter baumannii strains. Another in vitro study revealed that combination therapies (tigecycline/colistin and tigecycline/sulbactam) could achieve lower mutant prevention concentrations (MPCs) of tigecycline than tigecycline use alone [17]. A review showed that tigecycline plus sulbactam, carbapenem, or rifampicin showed synergistic effects against different bacteria [18]. Cefoperazone/sulbactam, the combination of a thirdgeneration cephalosporin and a $\beta$-lactamase inhibitor, is mostly used in China to treat severe bacterial infections and as a combination therapy with tigecycline to treat drug-resistant pathogens. It has low renal toxicity and high safety levels [19], but long-term high-dose use may lead to vitamin Kdependent coagulation dysfunction. $\mathrm{Hu}$ [20] reported a fatal vitamin $\mathrm{K}$-dependent coagulopathy associated with cefoperazone/sulbactam in a 79-year-old man with normal coagulation function and no history of blood or liver disease. However, whether cefoperazone/sulbactam combined with tigecycline aggravates coagulopathy or hypofibrinogenaemia is unclear.
We retrospectively analyzed the risk factors and clinical features of tigecycline-associated hypofibrinogenaemia and the coagulation function of hypofibrinogenaemic patients treated or not with cefoperazone/sulbactam.

\section{Materials and methods}

\section{Patients}

This retrospective case-control study was conducted at the First Affiliated Hospital of the Medical College of Zhejiang University, a 2500-bed tertiary-care teaching hospital, from January 1, 2017, to December 31, 2017. The hospital has a 73-bed intensive care unit (ICU), comprising a 29-bed medical ICU, a 15-bed emergent ICU, and a 29-bed surgical ICU. Patients with severe sepsis (according to sepsis 3.0) and treated with tigecycline (treatment for more than 3 days) were included in the study. All enrolled patients were greater than 18 years old, and the fibrinogen level before the use of tigecycline was greater than $2.0 \mathrm{~g} / \mathrm{L}$. Pregnant women and patients with incomplete medical records who received anticoagulant therapy or exogenous fibrinogen during treatment with tigecycline were excluded from the study. Patients who developed hypofibrinogenaemia after tigecycline treatment were included in the hypofibrinogenaemia $(<2.0 \mathrm{~g} / \mathrm{L})$ group, and the remaining patients were included in the normal fibrinogen group ( $\geq 2.0 \mathrm{~g} / \mathrm{L}$; normal group). Hypofibrinogenaemia was diagnosed if the fibrinogen level was $<2 \mathrm{~g} / \mathrm{L}$ for two consecutive days. The selection of patients is depicted in Fig. 1.

\section{Data collection}

The sex, age, and comorbidities of the study population were evaluated. The following parameters were also assessed at the time of tigecycline initiation: Sequential Organ Failure Assessment (SOFA) and Acute Physiology and Chronic Health Evaluation (APACHE) II scores, fibrinogen level, organ function (cardiac insufficiency, respiratory failure, shock, acute kidney injury, continuous renal replacement therapy, and liver function), infection indices (white blood cells, neutrophils, procalcitonin (PCT), and C-reactive protein (CRP)), sites of infection (bloodstream, lung, cranium, abdomen, skin, or urinary tract), use of empirical antifungal therapy, presence of pathogenic microorganisms (Acinetobacter baumannii, Klebsiella pneumoniae, Burkholderia cepacia, Stenotrophomonas maltophilia, or others), and therapeutic regimen (loading dose of $50 \mathrm{mg}, 100 \mathrm{mg}$, or more than $100 \mathrm{mg}$; maintenance dose of $50 \mathrm{mg}$ Q12H, $100 \mathrm{mg} \mathrm{Q12H,}$ or $50 \mathrm{mg} \mathrm{Q12H}$ and $100 \mathrm{mg} \mathrm{Q12H}$; treatment duration; and combination therapy of cefoperazone/sulbactam or sodium valproate). The incidence of common complications 
Fig. 1 The detailed patient selection process. ICU intensive care unit, FIB fibrinogen, CPZ/ SAM cefoperazone/sulbactam

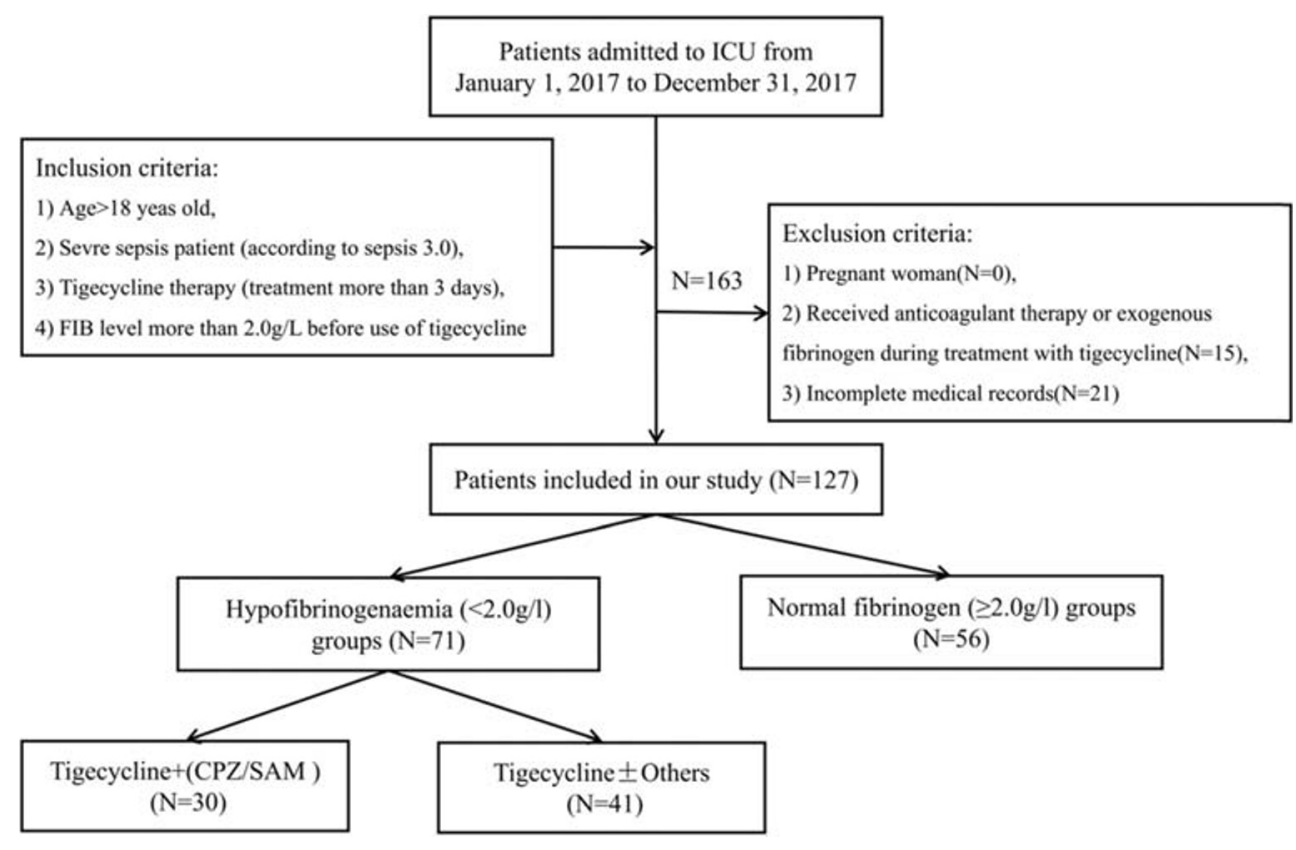

(coagulopathy, blood-product infusion, jaundice, severe bleeding) and the overall prognosis (length of ICU stay after starting tigecycline; total length of ICU stay, and 28-day ICU mortality rate) were also compared between the two groups.

To further analyze the effect of cefoperazone/sulbactam on coagulation in the hypofibrinogenaemia group, the minimum fibrinogen level, the time to hypofibrinogenaemia, and the time from discontinuation of tigecycline to normalization of the fibrinogen level were evaluated. Coagulopathy, jaundice, severe bleeding, and blood-product infusion were also compared between patients in the hypofibrinogenaemia group treated or not with cefoperazone/sulbactam.

\section{Definitions}

Liver dysfunction was defined as a serum bilirubin level of $>3 \mathrm{mg} / \mathrm{dL}$ and/or with a prothrombin time (PT) of $<$ $50 \%$, except in patients with jaundice, in whom it was defined as an increase in the serum bilirubin level or a PT of $<50 \%$ [21]. Kidney failure was defined as the criteria for stage 3 according to the Acute Kidney Injury Network (AKIN), which is an increase in serum creatinine ( $\mathrm{SCr}$ ) of more than $300 \%$ (>3-fold) from baseline or serum creatinine of more than or equal to $4.0 \mathrm{mg} / \mathrm{dL} \mathrm{(} \geq$ $354 \mu \mathrm{mol} / \mathrm{L}$ ) with an acute increase of at least $0.5 \mathrm{mg} /$ $\mathrm{dL}(44 \mu \mathrm{mol} / \mathrm{L})$ or urine output less than $0.3 \mathrm{~mL} / \mathrm{kg}$ per hour for $24 \mathrm{~h}$ or anuria for $12 \mathrm{~h}$ [22]. Cardiac insufficiency was defined as the New York College of Cardiology classes II-IV. Acute kidney injury was defined according to the 2012 KDIGO (Kidney Disease: Improving Global Outcomes) Clinical Practice Guidelines for Acute Kidney
Injury as any of the following: an increase in the SCr of $\geq$ $0.3 \mathrm{mg} / \mathrm{dL}(\geq 26.5 \mu \mathrm{mol} / \mathrm{L})$ within $48 \mathrm{~h}$, an increase in the $\mathrm{SCr}$ to $\geq 1.5$-fold of the baseline value known or presumed to have occurred within the prior 7 days, or a urine volume of $<0.5 \mathrm{~mL} / \mathrm{kg} / \mathrm{h}$ for $6 \mathrm{~h}$. Coagulopathy was defined as an INR of $>1.5$ or an APTT of $>60$ s [23]. Multiple drug resistance (MDR) is defined as nonsusceptibility to at least one agent in three or more antimicrobial categories. Extensively drug-resistant bacteria (XDR) are defined as being non-susceptible to at least one agent in all but two or fewer antimicrobial categories (i.e., bacterial isolates remain susceptible to only one or two categories) [24].

\section{Statistical analysis}

Statistical analysis was performed using Statistical Package for Social Sciences ver. 19.0. Continuous variables are presented as the mean \pm standard deviation (SD) (normal distribution) or as medians and interquartile range (non-normal distribution) and were evaluated by the $t$ test or MannWhitney $U$ test, as appropriate. A chi-squared test was used for categorical variables, and univariate and multivariate analyses were performed using logistic regression models to identify independent risk factors for tigecyclineassociated hypofibrinogenaemia. All biologically plausible variables significant at $p<0.10$ in univariate analyses were entered into a multivariate forward logistic regression analysis. A $p$ value $<0.05$ was considered to indicate statistical significance. 


\section{Results}

\section{Demographics of the study population}

During the study period, 127 critically ill patients with severe infections treated with tigecycline in the medical, surgical, or emergent ICU were enrolled. With the exception of 16 patients who were treated with empirical antibacterial therapy, the patients were infected with drug-resistant bacteria (multiple drug resistant (MDR) or extensively drug resistant (XDR)). Of these patients, $71(56 \%)$ developed hypofibrinogenaemia and were placed in the hypofibrinogenaemia group, and the other 56 were placed in the normal fibrinogen group ( $\geq 2.0 \mathrm{~g} / \mathrm{L}$; normal group). The mean ages of the patients in the hypofibrinogenaemia and normal groups were $63.72 \pm 15.68$ and $55.82 \pm 18.59$ years, respectively $(p=0.061)$. Males accounted for $79 \%$ of the patients $(77.5 \%$ in the hypofibrinogenaemia group and $80.4 \%$ in the normal group, $p=0.692$ ). There was no significant difference in the prevalence of chronic obstructive pulmonary disease, hypertension, diabetes mellitus, coronary heart disease, arrhythmia, solid organ tumour, autoimmune disease, cerebrovascular accident, liver failure, chronic renal failure, or surgery between the hypofibrinogenaemia and normal groups (Table 1).

\section{Clinical features of patients with hypofibrinogenaemia}

In the hypofibrinogenaemia group, hypofibrinogenaemia developed 1 to 25 days after the initiation of tigecycline, with a median (25-75th percentile) of 6 (4-8) days (Fig. 2). Among the patients in the hypofibrinogenaemia group, $51(72 \%)$ patients discontinued tigecycline treatment (due to medical improvement, drug resistance, economic position, serious complications, or other factors). Among these patients, the fibrinogen level did not return to the normal range in two patients, and seven patients had incomplete data; the fibrinogen level of the remaining $42(42 / 51,82 \%)$ patients normalized within a median of 3 (3-5) days (Fig. 3).

\section{Risk factors for hypofibrinogenaemia}

The risk factors for hypofibrinogenaemia are listed in Table 2 . In univariate analyses, the development of hypofibrinogenaemia was significantly associated with the fibrinogen level before starting tigecycline $(3.91 \pm 1.41 \mathrm{~g} / \mathrm{L}$ in the hypofibrinogenaemia group vs. $5.27 \pm 1.90 \mathrm{~g} / \mathrm{L}$ in the normal group, $p<0.001)$, intra-abdominal infection $(p=0.008)$, and therapeutic regimen (initial dose, maintenance dose, and treatment duration), but not the SOFA or APACHE II scores, organ function, infection indices, other infection sites (bloodstream, lung, cranium, skin, or urinary tract), use of empirical antibacterial therapy, and pathogenic microorganisms at the time of tigecycline initiation. A loading dose of $50 \mathrm{mg}$ (16.9\% (12) patients in the hypofibrinogenaemia group vs. $32.1 \%(18)$ in the normal group, $p=0.045$ ) and a maintenance dose of $50 \mathrm{mg}$ Q12H (33 (46.5\%) vs. $38(67.9 \%), p=0.016)$ protected against hypofibrinogenaemia. The median tigecycline duration in the hypofibrinogenaemia group was $11(8-16)$
Table 1 Demographics of the study population

\begin{tabular}{llllll}
\hline Variable & $\begin{array}{l}\text { Hypofibrinogenaemia } \\
\text { groups }(n=71)\end{array}$ & $\begin{array}{l}\text { Normal groups } \\
(n=56)\end{array}$ & OR & 95\% CI & $p$ \\
\hline Age (years) (mean \pm SD) & $63.72 \pm 15.68$ & $55.82 \pm 18.59$ & & & 0.061 \\
Sex (male, $n(\%))$ & $55(77.5)$ & $45(80.4)$ & 0.840 & $0.355-1.991$ & 0.692 \\
COPD (\%) & $10(14.1)$ & $3(4.5)$ & 2.896 & $0.757-11.079$ & 0.107 \\
Hypertension (\%) & $31(43.7)$ & $25(44.6)$ & 0.961 & $0.475-1.946$ & 0.912 \\
DM (\%) & $17(23.9)$ & $16(28.6)$ & 0.787 & $0.355-.744$ & 0.555 \\
CHD (\%) & $5(7)$ & $7(12.5)$ & 0.530 & $0.159-1.771$ & 0.296 \\
Arrhythmia (\%) & $10(14.1)$ & $4(7.1)$ & 0.469 & $0.139-1.585$ & 0.215 \\
Solid organ tumour $(\%)$ & $19(26.8)$ & $11(19.6)$ & 0.669 & $0.288-1.554$ & 0.348 \\
Autoimmune disease ${ }^{\#}(\%)$ & $4(5.6)$ & $5(8.9)$ & 1.642 & $0.420-6.426$ & 0.711 \\
Cerebrovascular accident & $13(18.3)$ & $10(17.9)$ & 1.031 & $0.415-2.563$ & 0.948 \\
$\quad(\%)$ & & $2(3.6)$ & 2.045 & $0.382-10.962$ & 0.464 \\
Chronic liver disease* $(\%)$ & $5(7)$ & $6(10.7)$ & 0.498 & $0.133-1.857$ & 0.469 \\
Chronic renal failure\# $(\%)$ & $4(5.6)$ & $23(41.1)$ & 1.395 & $0.688-2.829$ & 0.356 \\
Surgery in the past medical & $35(49.3)$ & & & & \\
$\quad$ history $(\%)$ & & & & & \\
\hline
\end{tabular}

*Fisher's exact test, ${ }^{\#}$ continuity correction chi-square test, and \& history of surgery and non-invasive procedures, such as endoscopy or colonoscopy, are excluded from this category

$O R$ odds ratio, $C I$ confidence interval, $C O P D$ chronic obstructive pulmonary disease, $D M$ diabetes mellitus, $C H D$ coronary heart disease 


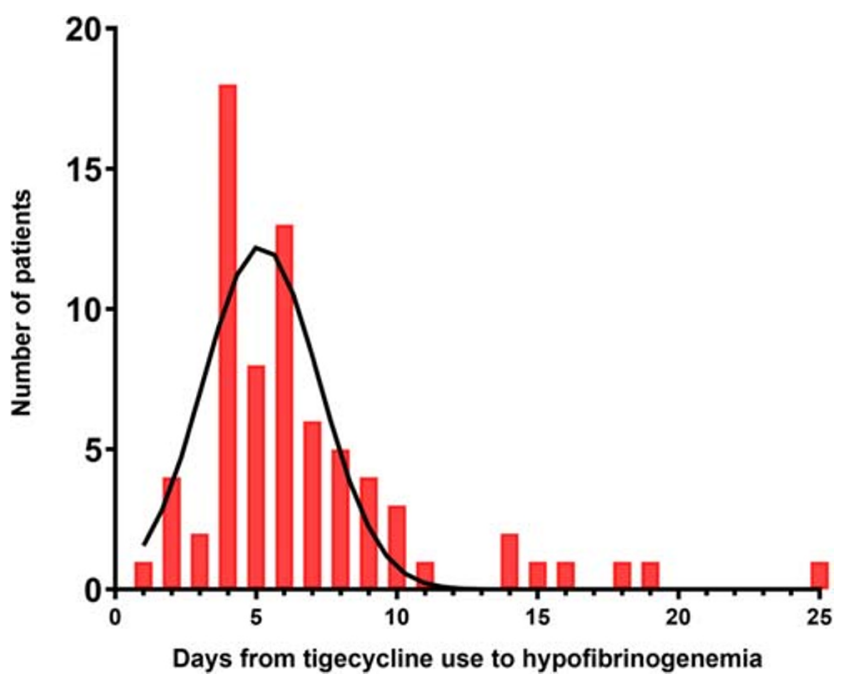

Fig. 2 The distribution of time (days) from tigecycline use to hypofibrinogenaemia in hypofibrinogenaemia group. Patients developed hypofibrinogenaemia from 1 to 25 days after initiation of tigecycline, with a median (25-75th percentile) of 6 (4-8) days in the hypofibrinogenaemia group $(n=71)$

days, significantly longer than that in the normal group, or 6 (3-16.75 days, $p=0.001)$. However, combination therapies, cefoperazone/sulbactam $(p=0.286)$ and sodium valproate $(p=0.696)$, were used in similar proportions of patients in the two groups.

The following variables that were significant at $p<0.10$ in the univariate analyses were included in the multivariate analysis: fibrinogen level, APACHE II scores, neutrophil count, presence of intra-abdominal infection, loading dose,

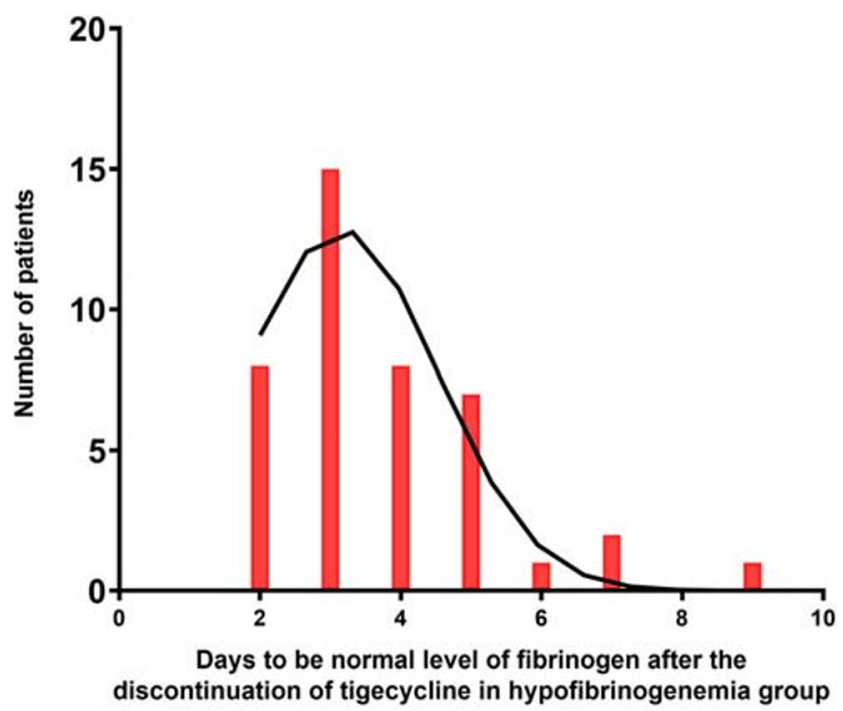

Fig. 3 The distribution of time (days) to recover to level of fibrinogen after the discontinuation of tigecycline in hypofibrinogenaemia group. Fifty-one patients discontinued tigecycline treatment in hypofibrinogenaemia group. Fibrinogen level did not return to the normal range in two patients and seven patients had incomplete data; the fibrinogen level of the remaining $42(82 \%)$ patients normalized within a median of $3(3-5)$ days maintenance dose, and treatment duration. In the multivariate analysis, the presence of intra-abdominal infection $(p=$ $0.005)$, fibrinogen level $(p<0.001)$, maintenance dose $(p=$ $0.039)$, and treatment course $(p=0.002)$ were related to hypofibrinogenaemia (Table 3 ).

\section{Clinical complications and outcomes}

Compared with that in the normal group, a greater proportion of the patients in the hypofibrinogenaemia group developed coagulopathy $(p<0.001)$ and required additional blood products $(p<0.001)$, but there was no significant difference in the incidence of jaundice $(p=0.407)$, severe bleeding $(p=0.129)$, and 28-day ICU mortality rate $(p=0.444)$. Moreover, the patients with hypofibrinogenaemia had an increased ICU stay duration after starting tigecycline (19 (10-31) vs. 6 (3.25$16.75)$ days, $p<0.001)$ and an increased total ICU stay duration (30 (19-48) vs. 13 (5-23) days, $p=0.040)$. Moreover, we found that patients in our study had an increased 28-day ICU mortality rate $(52.1 \%$ in the hypofibrinogenaemia group and $58.9 \%$ in the normal group; Table 4).

\section{Clinical features of hypofibrinogenaemic patients treated with cefoperazone/sulbactam}

In the hypofibrinogenaemia group, $30(42 \%)$ patients were treated with cefoperazone/sulbactam, and there was no difference in the incidence of hypofibrinogenaemia between the patients who were and were not treated with cefoperazone/ sulbactam. Compared with the patients not treated with cefoperazone/sulbactam, these patients had a higher rate of coagulopathy $(p=0.009)$ and needed more blood products $(p=0.003)$, but there was no difference in the lowest fibrinogen levels, rate of jaundice or severe bleeding, time to hypofibrinogenaemia, or time from discontinuation of tigecycline to normalization of the fibrinogen level (Table 5).

\section{Discussion}

The manufacturer lists gastrointestinal symptoms as the most common adverse reaction to tigecycline, and atypical adverse reactions involve the blood and lymphatic system (incidence, 2\%), APTT and PT prolongation, an increased eosinophil count, an increased INR, and a decreased platelet count [5]. Several severe cases of tigecycline-associated coagulopathy and hypofibrinogenaemia have been reported.

Fibrinogen is a glycosylated acute-phase protein synthesized by liver parenchymal cells that has a half-life of 3 to 4 days. The normal range of the fibrinogen level in the bloodstream is 2 to $4 \mathrm{~g} / \mathrm{L}$. Hypofibrinogenaemia can occur in patients with chronic inherited diseases such as afibrinogenaemia, dysfibrinogenaemia, or 
Table 2 Univariate analysis of risk factors for tigecycline-associated hypofibrinogenaemia

\begin{tabular}{|c|c|c|c|c|c|c|}
\hline \multicolumn{2}{|l|}{ Variable } & Hypofibrinogenaemia groups $(n=71)$ & Normal groups $(n=56)$ & OR & $95 \% \mathrm{CI}$ & $p$ \\
\hline \multicolumn{7}{|c|}{ Index when starting to use tigecycline } \\
\hline \multicolumn{2}{|c|}{ SOFA scores } & $9.54 \pm 6.20$ & $10.95 \pm 7.23$ & 0.969 & $0.919-1.021$ & 0.239 \\
\hline \multicolumn{2}{|l|}{ APACHE II scores } & $11.82 \pm 6.20$ & $11.95 \pm 7.99$ & 0.997 & $0.949-1.049$ & 0.055 \\
\hline \multicolumn{2}{|c|}{ Fibrinogen level $(\mathrm{g} / \mathrm{L})$} & $3.92 \pm 1.41$ & $5.27 \pm 1.90$ & 0.601 & $1.465-0.775$ & $<0.001$ \\
\hline \multicolumn{7}{|c|}{ Organ function when starting to use tigecycline } \\
\hline \multicolumn{2}{|c|}{ Cardiac insufficiency $(\%)$} & $1(1.4)$ & $4(7.1)$ & 0.186 & $0.020-1.711$ & 0.137 \\
\hline \multicolumn{2}{|c|}{ Respiratory failure $(\%)$} & $61(85.9)$ & $50(89.3)$ & 0.732 & $0.249-2.153$ & 0.571 \\
\hline \multicolumn{2}{|l|}{ Shock $(\%)$} & $27(38)$ & $21(37.5)$ & 1.023 & $0.496-2.107$ & 0.951 \\
\hline \multirow[t]{2}{*}{ Kidney } & $\mathrm{AKI}(\%)$ & $30(42.3)$ & $22(39.3)$ & 1.131 & $0.554-2.309$ & 0.736 \\
\hline & CRRT $(\%)$ & $20(28.2)$ & $14(25)$ & 1.176 & $0.531-2.607$ & 0.689 \\
\hline \multirow[t]{4}{*}{ Liver } & $\mathrm{ALB}(\mathrm{g} / \mathrm{L})$ & $32.84 \pm 4.64$ & $31.82 \pm 5.19$ & 1.044 & $0.969-1.126$ & 0.254 \\
\hline & $\mathrm{TB}(\mu \mathrm{mol} / \mathrm{L})$ & $16.5(10.25-32.25)$ & $14.5(10-24.75)$ & 0.999 & $0.991-1.008$ & 0.892 \\
\hline & $\mathrm{DB}(\mu \mathrm{mol} / \mathrm{L})$ & $10(5-21.51)$ & $7(4.25-13.75)$ & 0.999 & $0.988-1.011$ & 0.909 \\
\hline & INR & $1.25(1.15-1.36)$ & $1.1(1.10-1.30)$ & 1.369 & $0.383-4.894$ & 0.629 \\
\hline \multicolumn{7}{|c|}{ Infection index when starting to use tigecycline } \\
\hline \multirow[t]{3}{*}{ WBC $(\times 10 \mathrm{E} 9)$} & $<4(\%)$ & $6(8.5)$ & $2(3.5)$ & 0.607 & $0.285-1.292$ & 0.195 \\
\hline & $4-10(\%)$ & $28(39.4)$ & $17(30.4)$ & & & \\
\hline & $>10(\%)$ & $37(52.1)$ & $37(66.1)$ & & & \\
\hline \multicolumn{2}{|l|}{ Neutrophil (\%) } & $88.03 \pm 6.77$ & $85.602 \pm 9.17$ & 1.040 & $0.993-1.090$ & 0.095 \\
\hline \multicolumn{2}{|l|}{$\mathrm{CRP}(\mathrm{mg} / \mathrm{L})$} & $117.34 \pm 69.03$ & $131.56 \pm 108.22$ & 0.998 & $0.994-1.002$ & 0.371 \\
\hline \multicolumn{2}{|l|}{ PCT (ng/mL) } & $1.15(0.49-4.98)$ & $0.7(0.36-2.82)$ & 1.008 & $0.981-1.036$ & 0.552 \\
\hline \multicolumn{7}{|c|}{ Infected site } \\
\hline \multicolumn{2}{|c|}{ Bloodstream infection (\%) } & $25(35.2)$ & $16(28.6)$ & 1.359 & $0.637-2.897$ & 0.428 \\
\hline \multicolumn{2}{|c|}{ Pneumonia $(\%)$} & $46(64.8)$ & $39(69.6)$ & 0.802 & $0.379-1.697$ & 0.564 \\
\hline \multicolumn{2}{|c|}{ Intracranial infection $(\%)$} & $4(5.6)$ & $4(7.1)$ & 0.776 & $0.185-3.251$ & 0.729 \\
\hline \multicolumn{2}{|c|}{ Intra-abdominal infection $(\%)$} & $16(22.5)$ & $2(3.6)$ & 7.855 & $1.723-35.811$ & 0.008 \\
\hline Skin infection $(\%)$ & & $2(2.8)$ & $4(7.1)$ & 0.377 & $0.066-2.136$ & 0.270 \\
\hline Urinary tract infection & (\%) & $5(7)$ & $3(5.4)$ & 1.338 & $0.306-5.858$ & 0.699 \\
\hline Empirical antibacteria & therapy $(\%)$ & $6(8.5)$ & $10(17.9)$ & 0.425 & $0.144-1.251$ & 0.120 \\
\hline Two or more than (\%) & & $27(38)$ & $20(35.7)$ & 1.105 & $0.534-2.285$ & 0.789 \\
\hline Pathogenic microorgani & & & & & & \\
\hline Acinetobacter baumar & nii $(\%)$ & $28(39.4)$ & $27(48.2)$ & 0.699 & $0.345-1.420$ & 0.322 \\
\hline Klebsiella pneumonia & $(\%)$ & $34(47.9)$ & $28(50)$ & 0.919 & $0.456-1.852$ & 0.813 \\
\hline Burkholderia cepacia & (\%) & $5(7)$ & $4(7.1)$ & 0.985 & $0.252-3.853$ & 0.982 \\
\hline Pseudomonas maltopl & ilia $(\%)$ & $6(8.5)$ & $2(3.6)$ & 2.492 & $0.483-12.855$ & 0.275 \\
\hline Others $(\%)$ & & $24(33.8)$ & $12(21.4)$ & 1.872 & $0.836-4.191$ & 0.124 \\
\hline Two or more than (\%) & & $23(41.1)$ & $24(33.8)$ & 0.733 & $0.355-1.512$ & 0.400 \\
\hline Therapeutic regimen & & & & & & \\
\hline Loading dose & $50 \mathrm{mg}(\%)$ & $12(16.9)$ & $18(32.1)$ & 0.429 & $0.186-0.991$ & 0.045 \\
\hline & $100 \mathrm{mg}$ or more than $(\%)$ & $59(83.1)$ & $38(67.9)$ & 2.376 & $1.009-5.376$ & 0.045 \\
\hline Maintenance dose & 50 or $100 \mathrm{mg}$ Q12H (\%) & $16(22.5)$ & $6(10.7)$ & 2.424 & $0.880-6.679$ & 0.081 \\
\hline & $50 \mathrm{mg}$ Q12H (\%) & $33(46.5)$ & $38(67.9)$ & 0.411 & $0.198-0.853$ & 0.016 \\
\hline & 100 mg Q12H (\%) & $22(31)$ & $12(21.4)$ & 1.646 & $0.730-3.711$ & 0.227 \\
\hline Maintenance dose & $50 \mathrm{mg}$ Q12H (\%) & $33(46.5)$ & $38(67.9)$ & 1.752 & $1.066-2.878$ & 0.027 \\
\hline & $100 \mathrm{mg}$ Q12H (\%) & $22(31)$ & $12(21.4)$ & & & \\
\hline & 50 or $100 \mathrm{mg} \mathrm{Q} 12 \mathrm{H} \mathrm{( \% )}$ & $16(22.5)$ & $6(10.7)$ & & & \\
\hline Treatment duration & & $11(8-16)$ & $6(3-16.75)$ & 1.121 & $1.046-1.202$ & 0.001 \\
\hline Combination therapy & Sodium valproate (\%) & $5(7)$ & $5(8.9)$ & 0.773 & $0.212-2.814$ & 0.696 \\
\hline & CPZ/SAM $(\%)$ & $30(42.3)$ & $29(51.8)$ & 0.681 & $0.337-1.378$ & 0.286 \\
\hline
\end{tabular}

OR odds ratio, $C I$ confidence interval, SOFA Sequential Organ Failure Assessment, APACHE Acute Physiology and Chronic Health Evaluation, AKI acute kidney injury, $C R R T$ continuous renal replacement therapy, $A L B$ albumin, $A L T$ alanine transaminase, $T B$ total bilirubin, $D B$ direct bilirubin, $I N R$ international normalized ratio, $W B C$ white blood cells, $C R P$ C-reactive protein, $P C T$ procalcitonin, $C P Z / S A M$ cefoperazone/sulbactam

hypodysfibrinogenaemia [25]; patients with acquired hepatic dysfunction, such as cirrhosis, hepatitis, and metastatic hepatoma [26]; and patients with severe malnutrition. Acute hypofibrinogenaemia is associated with disseminated intravascular coagulation (DIC), severe sepsis, malignancy, and drug administration (valproic acid, synthetic adrenocorticotropic hormone (ACTH), prednisolone, L-asparaginase, allopurinol, and tigecycline) [4]. In this study, there was no difference in medical history, age, sex, or infection indices or liver function at the time of tigecycline initiation between the two groups. Indeed, the fibrinogen levels of 42 out of 51 patients recovered after the discontinuation of tigecycline. Therefore, all of the cases of hypofibrinogenaemia were most likely caused by tigecycline. 
Table 3 Multivariate analysis of risk factors for tigecyclineassociated hypofibrinogenaemia

\begin{tabular}{llll}
\hline Variable & OR & $95 \%$ CI & $p$ \\
\hline Maintenance dose & 1.998 & $1.037-3.849$ & 0.039 \\
Treatment course & 1.152 & $1.053-1.260$ & 0.002 \\
Fibrinogen level when staring to use tigecycline & 0.558 & $0.414-0.752$ & $<0.001$ \\
Intra-abdominal infection & 11.420 & $2.069-63.050$ & 0.005 \\
\hline
\end{tabular}

$O R$ odds ratio, $C I$ confidence interval
In the hypofibrinogenaemia group, 71 patients $(56 \%)$ developed hypofibrinogenaemia at a median (25-75th percentile) of 6 (4-8) days. This is in agreement with prior reports: Sabanis et al. [4] showed that coagulation parameters worsened markedly on day 7 after the start of tigecycline, and Rossitto et al. [7] and Duran et al. [11] demonstrated that hypofibrinogenaemia developed on days 5 and 10, respectively. Routsi et al. [7], in a study of 45 ICU patients on tigecycline, reported that a progressive increase in the plasma fibrinogen concentration occurred from day 0 to 7 and in two case reports on days 2 and 19 [4, 10]. In this study, the fibrinogen level of $82 \%$ of the patients $(42 / 52)$ returned to within the normal range in a median of $3(3-5)$ days. This is also in accord with previous cases [4, 7-11]. Hypofibrinogenaemia induced by tigecycline has not been analyzed in large clinical trials, and the risk factors for tigecycline-associated hypofibrinogenaemia are unclear. Only two clinical studies $[5,12]$ have reported a significantly decreased fibrinogen level in patients treated with a high dose, and Wu et al. [10] showed that female sex, renal insufficiency, and a high dose may be risk factors for adverse reactions in patients with tigecyclineassociated coagulation disorder. Univariate analyses in our study also showed that the maintenance dose $(p=0.027)$ was a risk factor for hypofibrinogenaemia, and a loading dose of $50 \mathrm{mg}(p=0.045)$ and maintenance dose of $50 \mathrm{mg} \mathrm{Q12H}$ ( $p=0.016$ ) may protect against hypofibrinogenaemia.

Although a maintenance dose of $50 \mathrm{mg} \mathrm{Q12H}$ may be a protective factor for normal fibrinogen levels, the pharmacokinetic/pharmacodynamic properties of tigecycline suggest that high-dose (HD) (100 mg Q12H) regimens may be more effective than low-dose (LD) (50 mg Q12H) regimens. Cunha and colleagues first reported that HD tigecycline is effective and it became the preferred dosing regimen for treating serious systemic infections due to susceptible and MDR pathogens [27]; thereafter, some studies confirmed HD tigecycline is associated with improved outcomes (including clinical outcome, microbiological eradication rate, increased survival time, and decreased mortality) compared with LD tigecycline [28-32]. However, a retrospective study including 134 patients who were diagnosed with ventilatorassociated pneumonia (VAP) showed no significant difference in the incidence of 28-day mortality among different dose groups (LD, HD, and non-standard HD groups) [33]. In addition, a meta-analysis including 17 studies (11 studies from China, 3 published in English, and 8 in Chinese) showed that all-cause mortality for patients treated with HD tigecycline was significantly lower than that for patients treated with LD tigecycline; however, subgroup analyses by country showed no significant difference in the non-Chinese studies. The microbiological eradication rate of the HD regimen was also significantly higher than that of the LD regimen, whereas a non-Chinese study presented a negative result in the subgroup analyses [34]. Hence, both efficacy and safety should be taken into account when a physician chooses tigecycline as an antibacterial agent.

In the multivariate analysis, intra-abdominal infection was found to be related to hypofibrinogenaemia $(p=0.008)$ but not pathogenic bacteria. This may be linked to the mechanism

Table 4 Clinical complications and outcomes of patients with severe infections treated with tigecycline in ICU

\begin{tabular}{|c|c|c|c|c|c|}
\hline Variable & $\begin{array}{l}\text { Hypofibrinogenaemia } \\
\text { groups }(n=71)\end{array}$ & Normal groups $(n=56)$ & OR & $95 \% \mathrm{CI}$ & $p$ \\
\hline Coagulopathy (\%) & $49(69)$ & $19(33.9)$ & 4.337 & $2.054-9.161$ & $<0.001$ \\
\hline Jaundice $(\%)$ & $17(23.9)$ & $10(17.9)$ & 1.448 & $0.604-3.472$ & 0.407 \\
\hline Severe bleeding ${ }^{\#}(\%)$ & $8(11.3)$ & $2(3.6)$ & 3.429 & $0.698-16.839$ & 0.129 \\
\hline Transfusion blood products (\%) & $42(68.9)$ & $15(26.8)$ & 6.042 & $2.709-13.476$ & $<0.001$ \\
\hline Lengths of ICU stay after using tigecycline (days) & $19(10-31)$ & $6(3.25-16.75)$ & 1.012 & $0.997-1.028$ & $<0.001$ \\
\hline Total lengths of ICU stay (days) & $30(19-48)$ & $13(5-23)$ & 1.014 & $1.001-1.028$ & 0.040 \\
\hline 28-day ICU mortality (\%) & $37(52.1)$ & $33(58.9)$ & 0.758 & $0.374-1.539$ & 0.444 \\
\hline
\end{tabular}

$O R$ odds ratio, $C I$ confidence interval, $I C U$ intensive care unit 
Table 5 Clinical symptoms of patients treated with cefoperazone/sulbactam in the hypofibrinogenaemia group

\begin{tabular}{|c|c|c|c|c|c|c|}
\hline \multicolumn{2}{|l|}{ Variable } & $\begin{array}{l}\text { Tigecycline + CPZ/SAM } \\
(n=30)\end{array}$ & $\begin{array}{l}\text { Tigecycline } \pm \text { others } \\
(n=41)\end{array}$ & OR & $95 \% \mathrm{CI}$ & $p$ \\
\hline \multicolumn{2}{|l|}{ Sex (male, $n(\%))$} & $25(83.3)$ & $30(73.2)$ & 1.833 & $0.562-5.984$ & 0.315 \\
\hline \multicolumn{2}{|c|}{ Age (years) $($ mean $\pm \mathrm{SD})$} & $67.20 \pm 14.46$ & $61.17 \pm 16.13$ & 1.027 & $0.994-1.061$ & 0.113 \\
\hline \multicolumn{7}{|c|}{ Index when starting to use tigecycline } \\
\hline \multicolumn{2}{|c|}{ SOFA scores } & $9.97 \pm 5.98$ & $9.22 \pm 6.41$ & 1.020 & $0.945-1.010$ & 0.614 \\
\hline \multicolumn{2}{|l|}{ APACHE II scores } & $12.17 \pm 5.88$ & $11.56 \pm 6.48$ & 1.016 & $0.941-1.097$ & 0.682 \\
\hline \multicolumn{2}{|c|}{ Fibrinogen level (g/L) } & $3.840 \pm 1.51$ & $3.966 \pm 1.36$ & 0.937 & $0.667-1.316$ & 0.706 \\
\hline \multicolumn{7}{|c|}{ Organ function when starting to use tigecycline } \\
\hline \multicolumn{2}{|c|}{ Respiratory failure $(\%)$} & $26(86.7)$ & $35(85.4)$ & 1.114 & $0.285-4.355$ & 0.876 \\
\hline \multicolumn{2}{|l|}{ Shock $(\%)$} & $14(46.7)$ & $13(31.7)$ & 1.885 & $0.712-4.988$ & $0.202-3$ \\
\hline \multirow[t]{2}{*}{ Kidney } & $\mathrm{AKI}(\%)$ & $16(53.3)$ & $14(34.1)$ & 2.204 & $0.840-5.785$ & 0.108 \\
\hline & CRRT (\%) & $8(26.7)$ & $12(29.3)$ & 0.879 & $0.307-2.517$ & 0.810 \\
\hline \multirow[t]{4}{*}{ Liver } & $\operatorname{ALB}(g / L)$ & $32.53 \pm 3.72$ & $33.08 \pm 5.30$ & 0.974 & $0.877-1.082$ & 0.624 \\
\hline & $\mathrm{TB}(\mu \mathrm{mol} / \mathrm{L})$ & $19(10.5-41.75)$ & $16(10-25.75)$ & 1.006 & $0.991-1.021$ & 0.413 \\
\hline & $\mathrm{DB}(\mu \mathrm{mol} / \mathrm{L})$ & $11.5(6-26)$ & $7(4-17.25)$ & 1.009 & $0.990-1.029$ & 0.351 \\
\hline & INR & $1.25(1.15-1.36)$ & $1.26(1.16-1.36)$ & 1.457 & $0.241-8.803$ & 0.682 \\
\hline \multicolumn{7}{|c|}{ Infection index when starting to use tigecycline } \\
\hline \multirow{3}{*}{ WBC $(\times 10 \mathrm{E} 9)$} & $<4(\%)$ & 3 & 3 & 0.650 & $0.311-1.358$ & 0.448 \\
\hline & $4-10(\%)$ & 14 & 14 & & & \\
\hline & $>10(\%)$ & 13 & 24 & & & \\
\hline \multicolumn{2}{|l|}{ Neutrophil (\%) } & $88.78 \pm 7.58$ & $88.21 \pm 6.19$ & 0.990 & $0.923-1.062$ & 0.787 \\
\hline \multicolumn{2}{|l|}{$\mathrm{CRP}(\mathrm{mg} / \mathrm{L})$} & $117.55 \pm 59.09$ & $117.18 \pm 76.20$ & 1.000 & $0.993-1.007$ & 0.982 \\
\hline PCT (ng/mL) & & $5.97 \pm 8.58$ & $7.29 \pm 17.54$ & 0.993 & $0.958-1.030$ & 0.716 \\
\hline Infected site & & & & & & \\
\hline \multicolumn{2}{|c|}{ Bloodstream infection (\%) } & $12(40)$ & $13(31.7)$ & 1.436 & $0.54-3.84$ & 0.471 \\
\hline \multicolumn{2}{|c|}{ Pneumonia $(\%)$} & $21(70)$ & $25(61)$ & 1.493 & $0.55-4.07$ & 0.433 \\
\hline Intracranial infectio & & $3(10)$ & $1(2.4)$ & 4.444 & $0.44-45.01$ & 0.207 \\
\hline Intra-abdominal inf & & $8(26.7)$ & $8(19.5)$ & 1.50 & $0.49-4.59$ & 0.477 \\
\hline Skin infection (\%) & & $1(3.3)$ & $1(2.4)$ & 1.379 & $0.83-22.97$ & 0.823 \\
\hline Urinary tract infecti & & $1(3.3)$ & $4(9.8)$ & 0.32 & $0.03-3.01$ & 0.318 \\
\hline Empirical antibacte & $\mathrm{y}(\%)$ & $1(3.3)$ & $5(12.2)$ & 0.248 & $0.03-2.25$ & 0.215 \\
\hline Two or more than & & $14(46.7)$ & $13(31.7)$ & 1.885 & $0.712-4.988$ & 0.202 \\
\hline Pathogenic microorg & & & & & & \\
\hline Acinetobacter baum & & $14(46.7)$ & $14(34.1)$ & 1.687 & $0.643-4.429$ & 0.288 \\
\hline Klebsiella pneumon & & $17(56.7)$ & $17(41.5)$ & 1.846 & $0.712-4.786$ & 0.207 \\
\hline Burkholderia cepac & & $2(6.7)$ & $3(7.3)$ & 0.905 & $0.142-5.781$ & 0.916 \\
\hline Pseudomonas maltc & & $4(13.3)$ & $2(4.9)$ & 3.000 & $0.512-17.585$ & 0.223 \\
\hline Others $(\%)$ & & $10(33.3)$ & $14(34.1)$ & 0.964 & $0.356-2.612$ & 0.943 \\
\hline Two or more than ( & & $10(33.3)$ & $13(31.7)$ & 1.247 & $0.462-3.363$ & 0.663 \\
\hline Therapeutic regimen & & & & & & \\
\hline Loading dose & $50 \mathrm{mg}(\%)$ & $4(13.3)$ & $8(19.5)$ & 0.635 & $0.172-2.342$ & 0.493 \\
\hline & $100 \mathrm{mg}$ or more than $(\%)$ & $26(87)$ & $33(80.4)$ & 0.635 & $0.172-2.342$ & 0.493 \\
\hline Maintenance dose & $50 \mathrm{mg} \mathrm{Q12H} \mathrm{( \% )}$ & $11(36.7)$ & $22(53.7)$ & 1.326 & $0.728-2.417$ & 0.357 \\
\hline & 100 mg Q12H (\%) & $11(36.7)$ & $11(26.8)$ & & & \\
\hline & 50 or 100 mg Q12H (\%) & $8(26.7)$ & $8(19.5)$ & & & \\
\hline Treatment duration & & $11.5(8-18)$ & $11(8-14)$ & 1.069 & $0.995-1.148$ & 0.068 \\
\hline Clinical features & & & & & & \\
\hline The lowest fibrinog & $(\mathrm{g} / \mathrm{L})$ & $1.12 \pm 0.43$ & $1.16 \pm 0.29$ & 0.729 & $0.189-2.821$ & 0.648 \\
\hline Day to be hypofibri & iia after using tigecycline (days) & $6(4-8.25)$ & $5(4-7)$ & 1.074 & $0.954-1.219$ & 0.236 \\
\hline Day to be normaliz & scontinuation of tigecycline (days) & $3(2.25-3.75)$ & $4(3-5)$ & 0.796 & $0.506-1.255$ & 0.326 \\
\hline Coagulopathy (\%) & & $26(86.7)$ & $23(56.1)$ & 5.087 & $1.502-17.232$ & 0.009 \\
\hline Jaundice $(\%)$ & & $9(30)$ & $8(19.5)$ & 1.768 & $0.589-5.302$ & 0.309 \\
\hline Severe bleeding $(\%$ & & $5(16.7)$ & $2(4.9)$ & 2.533 & $0.555-11.557$ & 0.230 \\
\hline Transfusion blood $\mathrm{p}$ & & $24(80)$ & 18 (43.9) & 5.111 & $1.724-15.151$ & 0.003 \\
\hline
\end{tabular}

OR odds ratio, CI confidence interval, SOFA Sequential Organ Failure Assessment, APACHE Acute Physiology and Chronic Health Evaluation, AKI acute kidney injury, $C R R T$ continuous renal replacement therapy, $A L B$ albumin, $A L T$ alanine transaminase, $T B$ total bilirubin, $D B$ direct bilirubin, $I N R$ international normalized ratio, $W B C$ white blood cells, $C R P$ C-reactive protein, $P C T$ procalcitonin, $C P Z / S A M$ cefoperazone/sulbactam

by which tigecycline induces hypofibrinogenaemia. Antibiotics in general are associated with coagulation disorders, as they reduce the microflora of the colon and the distal ileum, which synthesize vitamin $\mathrm{K}_{2}$ (menaquinone) 
[35]. The underlying mechanism for this effect is unclear. Moreover, intra-abdominal infection can further reduce the intestinal microflora.

Compared with the mortality due to sepsis in patients in a prior study [36], patients in our study had an increased 28-day ICU mortality rate (52.1\% vs. $58.9 \%)$. Increased SOFA scores $(9.54 \pm 6.20$ vs. $10.95 \pm 7.23)$ and multiple or extensively drug-resistant bacteria (40.9\% and $48.8 \%$ Acinetobacter baumannii and Klebsiella pneumoniae, respectively) may be an explanation; moreover, 41 patients suffering from bloodstream infection may be another reason.

Sulbactam enhances the activity of cefoperazone and is used in cases of moderate-to-severe infection [37, 38]. Longterm high-dose use of cefoperazone/sulbactam can cause vitamin $\mathrm{K}$ deficiency, leading to reduced levels of vitamin $\mathrm{K}-$ dependent coagulation factors and resulting in coagulation disorder. Although alteration of the microflora of the colon and the distal ileum, which synthesize vitamin $\mathrm{K}_{2}$, is a commonly cited mechanism of antibiotic-associated coagulopathy, the mechanism of hypofibrinogenaemia is unclear. It has been suggested that the tigecycline-mediated inhibition of cytokines interferes with fibrinogen production [9]. Sabanis et al. [4] showed that coagulopathy induced by the inhibition of MK-producing bacteria or by a direct effect on hepatic vitamin $\mathrm{K}$ activation and impaired liver function is implicated in the fibrinogen-level reduction. Furthermore, they recommended that the mechanisms be investigated, focusing on the role of genetic factors [4]. Therefore, further studies of the mechanisms underlying tigecycline-associated hypofibrinogenaemia are warranted.

This study has several limitations. First, it was a retrospective case-control study and thus might have been influenced by selection bias. Second, we analyzed all pathogenic bacteria as a group but not individually, even though the presence of pathogenic bacteria is not a risk factor; a confounding bias might have been avoided if we had analyzed the presence of individual bacterial species in the study. Third, the heterogeneity of ICU patients limited the statistical analysis; further randomized controlled trials with larger cohorts or animal studies are warranted. Despite these limitations, we identified several clinical features and risk factors of tigecyclineassociated hypofibrinogenaemia, which will facilitate further research in this field.

Hypofibrinogenaemia is an uncommon and lifethreatening side effect of tigecycline treatment and is easily overlooked. We suggest that patients treated with tigecycline should be monitored for changes in the INR, PT, APTT, and fibrinogen level, as well as adverse reactions, to avoid severe, life-threatening disturbances of coagulation.

Authors' contributions All authors contributed to the study conception and design. Material preparation, data collection, and analysis were performed by Juan Hu, Yi Zheng, and Yang-xiao Lai. The first draft of the manuscript was written by Juan Hu and all authors commented on previous versions of the manuscript. All authors read and approved the final manuscript.

Data availability The data used and/or analyzed in this study are available from the corresponding author on reasonable request.

\section{Compliance with ethical standards}

Conflict of interest The authors declare that they have no conflict of interest.

Ethics approval This retrospective study involving human participants was in accordance with the ethical standards of the institutional and national research committee and with the 1964 Helsinki Declaration and its later amendments or comparable ethical standards. The Institutional Review Board of the First Affiliated Hospital, College of Medicine, Zhejiang University, approved this study (2019IIT 1395).

Informed consent Informed consent was obtained from all individual participants included in the study.

Code availability Not applicable.

\section{References}

1. Kaewpoowat Q, Ostrosky-Zeichner L (2015) Tigecycline: a critical safety review. Expert Opin Drug Saf 14:335-342. https://doi.org/ 10.1517/14740338.2015.997206

2. Projan SJ (2000) Preclinical pharmacology of GAR-936, a novel glycylcycline antibacterial agent. Pharmacotherapy 20:219S-223S; discussion 224S-228S. https://doi.org/10.1592/phco.20.14.219s. 35046

3. Hylands J (2008) Tigecycline: a new antibiotic. Intensive Crit Care Nurs 24:260-263. https://doi.org/10.1016/j.iccn.2008.03.006

4. Sabanis N, Paschou E, Gavriilaki E, Kalaitzoglou A, Vasileiou S (2015) Hypofibrinogenemia induced by tigecycline: a potentially life-threatening coagulation disorder. Infect Dis (Lond) 47:743746. https://doi.org/10.3109/23744235.2015.1043942

5. Zhang Q, Zhou S, Zhou J (2015) Tigecycline treatment causes a decrease in fibrinogen levels. Antimicrob Agents Chemother 59: 1650-1655. https://doi.org/10.1128/aac.04305-14

6. McMahan J, Moenster RP (2017) Tigecycline-induced coagulopathy. Am J Health Syst Pharm 74:130-134. https://doi.org/10.2146/ ajhp150894

7. Rossitto G, Piano S, Rosi S, Simioni P, Angeli P (2014) Lifethreatening coagulopathy and hypofibrinogenaemia induced by tigecycline in a patient with advanced liver cirrhosis. Eur J Gastroenterol Hepatol 26:681-684. https://doi.org/10.1097/meg. 0000000000000087

8. Pieringer H, Schmekal B, Biesenbach G, Pohanka E (2010) Severe coagulation disorder with hypofibrinogenemia associated with the use of tigecycline. Ann Hematol 89:1063-1064. https://doi.org/10. 1007/s00277-010-0911-7

9. Wu P-C, Wu C-C (2018) Tigecycline-associated hypofibrinogenemia: a case report and review of the literature. IDCases 11:56-57. https://doi.org/10.1016/j.idcr.2018.01.003

10. Wu X, Zhao P, Dong L, Zhang X (2017) A case report of patient with severe acute cholangitis with tigecycline treatment causing coagulopathy and hypofibrinogenemia. Medicine (Baltimore) 96: e9124. https://doi.org/10.1097/md.0000000000009124 
11. Duran FY, Yildirim H, Sen EM (2018) A lesser known side effect of tigecycline: hypofibrinogenemia. Turk J Haematol 35:83-84. https://doi.org/10.4274/tjh.2017.0310

12. Routsi C, Kokkoris S, Douka E, Ekonomidou F, Karaiskos I, Giamarellou H (2015) High-dose tigecycline-associated alterations in coagulation parameters in critically ill patients with severe infections. Int J Antimicrob Agents 45:90-93. https://doi.org/10.1016/j. ijantimicag.2014.07.014

13. Cai Y, Wang R, Liang B, Bai N, Liu Y (2011) Systematic review and meta-analysis of the effectiveness and safety of tigecycline for treatment of infectious disease. Antimicrob Agents Chemother 55: 1162-1172. https://doi.org/10.1128/aac.01402-10

14. Prasad P, Sun J, Danner RL, Natanson C (2012) Excess deaths associated with tigecycline after approval based on noninferiority trials. Clin Infect Dis 54:1699-1709. https://doi.org/10.1093/cid/ cis 270

15. Tasina E, Haidich AB, Kokkali S, Arvanitidou M (2011) Efficacy and safety of tigecycline for the treatment of infectious diseases: a meta-analysis. Lancet Infect Dis 11:834-844. https://doi.org/10. 1016/s1473-3099(11)70177-3

16. Dong X, Chen F, Zhang Y, Liu H, Liu Y, Ma L (2014) In vitro activities of rifampin, colistin, sulbactam and tigecycline tested alone and in combination against extensively drug-resistant Acinetobacter baumannii. J Antibiot (Tokyo) 67:677-680. https:// doi.org/10.1038/ja.2014.99

17. Ni W, Cui J, Liang B, Cai Y, Bai N, Cai X, Wang R (2013) In vitro effects of tigecycline in combination with colistin (polymyxin E) and sulbactam against multidrug-resistant Acinetobacter baumannii. J Antibiot (Tokyo) 66:705-708. https://doi.org/10. 1038/ja.2013.84

18. Cai Y, Bai N, Liu X, Liang B, Wang J, Wang R (2016) Tigecycline: alone or in combination? Infect Dis (Lond) 48:491-502. https://doi. org/10.3109/23744235.2016.1155735

19. Durante-Mangoni E, Tripodi MF, Albisinni R, Utili R (2010) Management of Gram-negative and fungal endocarditis. Int $\mathrm{J}$ Antimicrob Agents 36(Suppl 2):S40-S45. https://doi.org/10.1016/ j.ijantimicag.2010.11.012

20. Hu HR (2019) Fatal vitamin K-dependent coagulopathy associated with cefoperazone/sulbactam: a case report. Drug SafCase Rep 6:6. https://doi.org/10.1007/s40800-019-0100-0

21. Capussotti L, Vigano L, Giuliante F, Ferrero A, Giovannini I, Nuzzo G (2009) Liver dysfunction and sepsis determine operative mortality after liver resection. Br J Surg 96:88-94. https://doi.org/ 10.1002/bjs.6429

22. Mehta RL, Kellum JA, Shah SV, Molitoris BA, Ronco C, Warnock DG, Levin A (2007) Acute kidney injury network: report of an initiative to improve outcomes in acute kidney injury. Crit Care 11:R31. https://doi.org/10.1186/cc5713

23. Glas GJ, Levi M, Schultz MJ (2016) Coagulopathy and its management in patients with severe burns. J Thromb Haemost 14:865874. https://doi.org/10.1111/jth.13283

24. Magiorakos AP, Srinivasan A, Carey RB, Carmeli Y, Falagas ME, Giske CG, Harbarth S, Hindler JF, Kahlmeter G, Olsson-Liljequist B, Paterson DL, Rice LB, Stelling J, Struelens MJ, Vatopoulos A, Weber JT, Monnet DL (2012) Multidrug-resistant, extensively drug-resistant and pandrug-resistant bacteria: an international expert proposal for interim standard definitions for acquired resistance. Clin Microbiol Infect 18:268-281. https://doi.org/10.1111/j. 1469-0691.2011.03570.x
25. Acharya SS, Dimichele DM (2008) Rare inherited disorders of fibrinogen. Haemophilia 14:1151-1158. https://doi.org/10.1111/j. 1365-2516.2008.01831.x

26. Mammen EF (1994) Coagulopathies of liver disease. Clin Lab Med 14:769-780. https://doi.org/10.1016/S0272-2712(18)30355-X

27. Cunha BA, McDermott B, Nausheen S (2007) Single daily highdose tigecycline therapy of a multidrug-resistant (MDR) Klebsiella pneumoniae and Enterobacter aerogenes nosocomial urinary tract infection. J Chemother 19:753-754. https://doi.org/10.1179/joc. 2007.19.6.753

28. Geng TT, Xu X, Huang M (2018) High-dose tigecycline for the treatment of nosocomial carbapenem-resistant Klebsiella pneumoniae bloodstream infections: a retrospective cohort study. Medicine (Baltimore) 97:e9961. https://doi.org/10.1097/md. 0000000000009961

29. De Pascale G, Montini L, Pennisi M, Bernini V, Maviglia R, Bello G, Spanu T, Tumbarello M, Antonelli M (2014) High dose tigecycline in critically ill patients with severe infections due to multidrugresistant bacteria. Crit Care 18:R90. https://doi.org/10.1186/ cc13858

30. Ramirez J, Dartois N, Gandjini H, Yan JL, Korth-Bradley J, McGovern PC (2013) Randomized phase 2 trial to evaluate the clinical efficacy of two high-dosage tigecycline regimens versus imipenem-cilastatin for treatment of hospital-acquired pneumonia. Antimicrob Agents Chemother 57:1756-1762. https://doi.org/10. 1128/aac.01232-12

31. Falagas ME, Vardakas KZ, Tsiveriotis KP, Triarides NA, Tansarli GS (2014) Effectiveness and safety of high-dose tigecycline-containing regimens for the treatment of severe bacterial infections. Int J Antimicrob Agents 44:1-7. https://doi.org/10.1016/j.ijantimicag. 2014.01.006

32. Baron J, Cai S, Klein N, Cunha BA (2018) Once daily high dose tigecycline is optimal: tigecycline $\mathrm{PK} / \mathrm{PD}$ parameters predict clinical effectiveness. J Clin Med 7:E49. https://doi.org/10.3390/ jcm7030049

33. Chen Z, Shi X (2018) Adverse events of high-dose tigecycline in the treatment of ventilator-associated pneumonia due to multidrugresistant pathogens. Medicine (Baltimore) 97:e12467. https://doi. org $/ 10.1097 / \mathrm{md} .0000000000012467$

34. Gong J, Su D, Shang J, Yu H, Du G, Lin Y, Sun Z, Liu G (2019) Efficacy and safety of high-dose tigecycline for the treatment of infectious diseases: a meta-analysis. Medicine (Baltimore) 98: e17091. https://doi.org/10.1097/md.0000000000017091

35. Shirakawa H, Komai M, Kimura S (1990) Antibiotic-induced vita$\min \mathrm{K}$ deficiency and the role of the presence of intestinal flora. Int $\mathrm{J}$ Vitam Nutr Res 60:245-251

36. Gotts JE, Matthay MA (2016) Sepsis: pathophysiology and clinical management. BMJ 353:i1585. https://doi.org/10.1136/bmj.i1585

37. Drawz SM, Bonomo RA (2010) Three decades of beta-lactamase inhibitors. Clin Microbiol Rev 23:160-201. https://doi.org/10. 1128/cmr.00037-09

38. Xin X, Jian L, Xia X, Jia B, Huang W, Li C, Wang C, Zhou L, Sun X, Tang X, Huang Y, Zhu Y, Zhang W (2013) A multicentre clinical study on the injection of ceftriaxone/sulbactam compared with cefoperazone/sulbactam in the treatment of respiratory and urinary tract infections. Ann Clin Microbiol Antimicrob 12:38. https://doi. org/10.1186/1476-0711-12-38

Publisher's note Springer Nature remains neutral with regard to jurisdictional claims in published maps and institutional affiliations. 